\title{
Die Verfassungsgarantie kommunaler Selbstverwaltung
}

Eine dogmatische Rekonstruktion

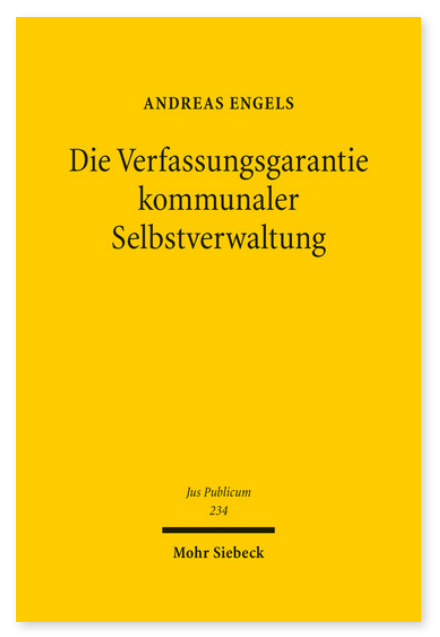

2014. XXVIII, 682 Seiten. JusPubl 234

ISBN 978-3-16-153417-1

DOI 10.1628/978-3-16-153417-1

eBook PDF 159,00€

ISBN 978-3-16-153355-6

Leinen $159,00 €$
Die Aktualität der Herausforderungen kommunaler Selbstverwaltung steht in deutlichem Gegensatz zur dogmatischen Entfaltung des Art. 28 Abs. 2 GG. Andreas Engels hat daher das Anliegen, mit Hilfe einer dogmatischen Rekonstruktion eine belastbare Basis zur Bewältigung der Herausforderungen kommunaler Selbstverwaltung zu schaffen. Der entwickelte Neuansatz erhebt dabei erklärtermaßen nicht den Anspruch, alle Fragestellungen zu beantworten. Wohl aber sollen Unzulänglichkeiten beseitigt werden, die auf Schwächen der bisherigen dogmatischen Deutungsmuster zurückzuführen sind. Der Autor will zur Rationalisierung der Argumentationsprozesse und zu einer höheren Konsistenz der Bereichsdogmatik beitragen.

Andreas Engels Geboren 1981; Studium der Rechtswissenschaften an der Universität zu Köln; 2004 Erstes Juristisches Staatsexamen; 2007 Zweites Juristisches Staatsexamen; 2007 Promotion; Akademischer Rat a. Z. am Institut für Staatsrecht der Universität zu Köln; 2013 Habilitation und Verleihung der venia legendi für die Fächer Staats- und Verwaltungsrecht sowie Gesundheitsrecht.

Jetzt bestellen:

https://mohrsiebeck.com/buch/die-verfassungsgarantie-kommunaler-selbstverwaltung-9783161534171?no_cache=1 order@mohrsiebeck.com

Telefon: +49 (0)7071-923-17

Telefax: $+49(0) 7071-51104$ 